\title{
YouTube provides irrelevant information for the diagnosis and treatment of hip arthritis
}

\author{
Ulrich Koller $^{1} \cdot$ Wenzel Waldstein ${ }^{1} \cdot$ Klaus-Dieter Schatz $^{1} \cdot$ Reinhard Windhager $^{1}$
}

Received: 10 January 2016/Accepted: 11 March 2016/Published online: 31 March 2016

(C) The Author(s) 2016. This article is published with open access at Springerlink.com

\begin{abstract}
Purpose YouTube is increasingly becoming a key source for people to satisfy the need for additional information concerning their medical condition. This study analyses the completeness of accurate information found on YouTube pertaining to hip arthritis.

Methods The present study analyzed 133 YouTube videos using the search terms: hip arthritis, hip arthritis symptoms, hip arthritis diagnosis, hip arthritis treatment and hip replacement. Two quality assessment checklists with a scale of 0 to 12 points were developed to evaluate available video content for the diagnosis and the treatment of hip arthritis. Videos were grouped into poor quality (grade $0-3$ ), moderate quality (grade 4-7) and excellent quality (grade 8-12), respectively. Three independent observers assessed all videos using the new grading system and independently scored all videos. Discrepancies regarding the categories were clarified by consensus discussion. For intra-observer reliabilities, grading was performed at two occasions separated by four weeks.
\end{abstract}

Wenzel Waldstein

wwaldstein@gmail.com

Ulrich Koller

ulrich.koller@meduniwien.ac.at

Klaus-Dieter Schatz

klaus-dieter.schatz@meduniwien.ac.at

Reinhard Windhager

reinhard.windhager@akhwien.at

1 Department of Orthopaedics, Vienna General Hospital, Medical University of Vienna, Waehringer Guertel 18-20,

1090 Vienna, Austria
Results Eighty-four percent $(n=112)$ had a poor diagnostic information quality, $14 \%(n=19)$ a moderate quality and only $2 \%(n=2)$ an excellent quality, respectively. In $86 \%(n=114)$, videos provided poor treatment information quality. Eleven percent $(n=15)$ of videos had a moderate quality and only $3 \%(n=4)$ an excellent quality, respectively.

Conclusions The present study demonstrates that YouTube is a poor source for accurate information pertaining to the diagnosis and treatment of hip arthritis. These finding are of high relevance for clinicians as videos are going to become the primary source of information for patients. Therefore, high quality educational videos are needed to further guide patients on the way from the diagnosis of hip arthritis to its proper treatment.

Keywords YouTube $\cdot$ Hip arthritis $\cdot$ Diagnosis $\cdot$ Treatment . Information quality

\section{Introduction}

Arthritis commonly affects the hip joint [1]. The disease, however, can have an insidious onset with pain as a late clinical feature [2]. Nearly $10 \%$ of North Americans over 45 years of age complain of symptomatic hip arthritis [3]. Total hip arthroplasty (THA) is considered the gold standard for endstage hip arthritis $[4,5]$. Approximately 380,000 primary total hip arthroplasties were to be performed in the United States in 2015 [6].

The Internet has become an important source for medical and health-related information [7].

More than $50 \%$ of North Americans with access to the Internet use the Internet for issues related to their health at least once a month $[8,9]$. Nevertheless, $86 \%$ of those "health seekers" are concerned about unreliable information and $44 \%$ 
think that they can only believe part of the information available on the Internet [9].

Online video is increasingly becoming a key source for people to satisfy their information needs. According to Cisco Systems Inc., video will account for $80 \%$ of all consumer internet traffic by 2019 [10]. YouTube is one of the most popular websites used for information exchange, with more than one billion unique visitors every month [11]. Threehundred hours of video material is uploaded every minute [11]. YouTube $E D U$ was launched in 2014. It features the most popular educational videos across YouTube and has currently more than 10 million subscribers. Unfortunately, there is, so far, no channel on topics related to orthopaedics.

In an attempt to participate in personal health care decisions, patients may access YouTube for further information. YouTube videos concerning the diagnosis and treatment of hip arthritis cover a broad spectrum from personal testimonies to educational videos. Physicians should be aware about the variable quality of information and the different sources of health information. As YouTube is a non peer-reviewed platform and little is known about the completeness of accurate information, the study aims to analyze available YouTube video material. The following research questions were asked: (1) What is the information quality of YouTube videos related to the diagnosis of hip arthritis and (2) what information for the treatment of hip arthritis can be found on YouTube?

\section{Material and methods}

A YouTube search was performed on December 23, 2014 for videos related to the diagnosis and the treatment of hip arthritis. The following search terms were used: (1) hip arthritis, (2) hip arthritis symptoms, (3) hip arthritis diagnosis, (4) hip arthritis treatment and (5) hip replacement. The standard YouTube filters were used displaying all videos by relevance. For each search term, only videos on the first three pages were included in the analysis assuming that users would not access videos beyond the third page. On the search day, the following information of each video was recorded: the Universal Resource Locator (URL), the video title, the number of total views, the duration in minutes, the date of publication, the number of likes and the number of dislikes. Duplicate videos, non-English videos, videos not related to human hip arthritis, videos related to inflammatory hip arthritis and videos with no audio support were excluded. After initial inclusion of 302 videos, 169 videos were excluded as they did not meet the inclusion criteria leaving 133 videos to be included in this study. The YouTube search for 'hip arthritis', 'hip arthritis diagnosis' or 'hip arthritis symptoms' resulted in 67 videos; and a search for 'hip arthritis treatment' and 'hip replacement' in 66 videos, respectively. The selection of search terms was based on the autocomplete keyword tool which suggests search terms based on popularity. The term arthritis was used instead of osteoarthritis to reflect the fact that all forms of noninflammatory arthritis were considered in the present study. There was no institutional review board approval required for the present study.

In order to assess the available YouTube video content for the diagnosis and the treatment of hip arthritis two new grading systems were developed. Similar to MacLeod et al. [11], current evidence [12-17] and expert opinion were used to design two new grading systems, one for the analysis of diagnostic information quality (Table 1) and a second for the assessment of treatment information quality (Table 2). Both grading systems had a scale of 0 to 12 . Videos were considered of good quality if they provided a high amount of accurate information, and videos of poor quality lacked accurate information. Depending on the weighting of the items, single points or half points were given for each mentioned item on the checklist (Tables 1 and 2). Videos were further categorized into the following: educational-physician, educational- non physician, commercial, technique, personal testimony or other.

Three independent observers assessed all videos using the new grading system and independently scored all videos. Discrepancies regarding the categories were clarified by consensus discussion (Fig. 1). Inter-observer reliabilities of the grading scale were evaluated for all videos. Intraobserver reliabilities were performed for 20 randomly selected videos. For intra-observer reliabilities, grading was performed at two occasions separated by four weeks.

Videos were grouped into poor quality (grade $0-3$ ), moderate quality (grade 4-7) and excellent quality (grade 8-12), respectively.

YouTube search algorithms are complex and constantly evolving. It is known that YouTube video rankings are influenced by previous online search behaviour. In order to determine the effect of time and location on the results of this study, a second search was undertaken nine months after the initial search. In an attempt to achieve search results independent of previous online search behaviour and also independent of topographical factors, The Onion Router (Tor) software (The Tor Project, Inc) was used. Tor is established free software to allow anonymous web browsing [18]. Tor aims to conceal its users' identities and their online activity [18]. As a result, conventional YouTube filters do not apply and results are independent of the region in which the search was performed. The second search was performed on September 22, 2015 using the same search terms.

The distributions of variables were tested in exploratory data analysis. A Kolmogorov-Smirnov test was used to identify normal distribution of the variables; however, variables did not meet the criteria for normal distribution. The Mann Whitney U-test or the Kruskal-Wallis test was performed to compare the distribution of variables. P-values less than 0.05 
Table 1 Diagnostic information quality assessment checklist with a total of 12 points
Diagnostic information

Points

Overall disease summary (1 point)

History

Location of hip pain (groin, lateral, buttock, anterior thigh, knee)

$\max 1$ point

Association of pain and activity or pain at night

Limitations with walking (i.e. reduced walking distance, limp, assisting devices,)

$\max 1$ point

$\max 1$ point

Difficulties with activities of daily living:

ascending stairs, raising from sitting, standing, bending to the floor, walking on

$\max 2$ points

flat surface, getting in and out of car or on/off bus, going shopping, putting

0.5 points each

on your socks/stockings, rising from bed, taking off your socks/stockings,

lying in bed, getting in and out of bath, sitting, getting on/off the toilet,

performance of heavy domestic duties, performing light domestic duties

Stiffness (after awaking in the morning, after sitting, resting in the day)

$\max 1$ point

Primary, secondary arthritis (DDH, femoral/acetabular osteotomy, trauma, osteonecrosis, infection, FAI, Paget's disease)

Physical exam

Limited range of motion (decreased flexion/internal rotation, flexion contracture, rotational contractures)

Leg length discrepancy

Imaging

Conventional radiographs (AP pelvis, AP hip)

$\max 1$ point

Advanced imaging if indicated (CT, MRI)

$\max 1$ point

$\max 1$ point

$D D H$ developmental dysplasia of the hip, $F A I$ femoroacetabular impingement, $A P$ anteroposterior, $C T$ computed tomography, MRI magnetic resonance imaging

One point was given for each mentioned item except 'difficulties with activities of daily living', for which 0.5 points were given for each activity mentioned were considered significant. Reliability as an estimate of internal consistency was calculated as Cronbach's alpha which measured the degree of correlation among items [19]. The
Cronbach's alpha was determined for the mean of the scores for all three observers. A Cronbach's alpha of 0.7 is widely accepted to be the cut off for an acceptable reliability, values
Table 2 Treatment information quality assessment checklist with a total of 12 points

\begin{tabular}{|c|c|}
\hline $\begin{array}{l}\text { Treatment information } \\
\text { Conservative treatment }\end{array}$ & Points \\
\hline $\begin{array}{l}\text { Patient education, NSAD, weight loss, activity modification } \\
\text { (avoidance of high impact activities, usage of cane for a short period), } \\
\text { hip injection, physical therapy (stretching, strengthening) } \\
\text { Surgical procedure }\end{array}$ & $\begin{array}{l}\max 3 \text { points } \\
1 \text { point each }\end{array}$ \\
\hline Explanation of concept of total hip replacement or hip resurfacing & $\max 1$ point \\
\hline Approach to the hip (anterior, anterolateral, lateral, posterior) & $\max 1$ point \\
\hline Bearing surface (MoP, $\mathrm{CoC}, \mathrm{MoM}, \mathrm{CoP})$ & $\max 1$ point \\
\hline Fixation (uncemented, cemented, hybrid) & $\max 1$ point \\
\hline Restoration of physiologic hip biomechanics (offset, leg length) & $\max 1$ point \\
\hline \multicolumn{2}{|l|}{ Postsurgical } \\
\hline $\begin{array}{l}\text { Post operative mobilization (hip precautions including no flex over } 90^{\circ} \text {, } \\
\text { adduction, internal rotation) and physiotherapy including rapid recovery }\end{array}$ & $\max 1$ point \\
\hline Outcome (improved function, pain free, improved quality of life) & $\max 1$ point \\
\hline \multicolumn{2}{|l|}{ Complications } \\
\hline $\begin{array}{l}\text { Infection, periprosthetic fracture, dislocation, nerve injury, vascular injury, } \\
\text { venous thromboembolism, heterotopic ossification, pneumonia, leg } \\
\text { length discrepancy, loosening }\end{array}$ & $\begin{array}{l}\max 2 \text { points } \\
0.5 \text { points each }\end{array}$ \\
\hline
\end{tabular}

NSAD nonsteroidal anti-inflammatory drugs

One point was given for each mentioned item except for the categories conservative treatment and complications, for which 0.5 points were given for each item mentioned 


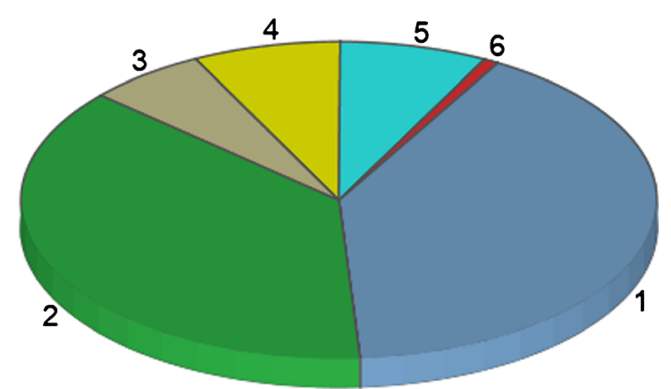

Fig. 1 Distribution of YouTube videos: 1: education-physician (40.6\%), 2: education- non physician $(37.6 \%), 3$ : commercial $(6 \%), 4$ : technique $(7.5 \%), 5$ : personal testimony $(7.5 \%)$ and 6 : other $(0.8 \%)$

between 0.7 and 0.9 are good, and values above 0.9 are considered excellent [20]. Intraobserver reliabilities of the grading scale were determined for 20 randomly selected videos by using single-measure intraclass correlation coefficients (ICC) with a two-way mixed model for absolute agreement [21]. Correlation was classified as poor $(0.00-0.20)$, fair $(0.21-$ $0.40)$, moderate $(0.41-0.60)$, good $(0.61-0.80)$, or excellent (0.81-1.00) [22]. Statistical tests were performed using SPSS 16.0 software for Windows (SPSS Inc, Chicago, IL, USA).

\section{Results}

After initial inclusion of 302 videos, 169 videos were excluded as they did not meet the inclusion criteria leaving 133 videos to be included in this study. Excellent intra-observer intraclass correlation coefficients (ICCs) were observed for diagnosis quality checklist (0.993) and the treatment quality checklist (0.957), respectively. Similarly, the Cronbach's alpha for the mean of all three independent observers showed excellent values for the diagnosis quality checklist (0.979) and the treatment quality checklist $(0.981)$, respectively.

The median number of views per day for all videos was 4.6, the median number of likes was eight and the median duration was five minutes. Analyzing videos according to the search term, it was observed that videos related to the search term 'hip replacement' had significantly $(\mathrm{p}<0.001)$ more views per day and significantly $(p=0.001)$ more 'likes' compared to videos related to the other search terms. Seventy-eight percent (18 of 23) of all videos with more than 30 views per day were found under the search term 'hip replacement'.

The vast majority of YouTube videos lack essential information for an appropriate diagnosis of hip arthritis. Analyzing all 133 videos, $84 \%(n=112)$ were graded as being of poor quality, $14 \%$ percent $(n=19)$ of moderate quality and only 2 $\%(n=2)$ of excellent quality (Fig. 2; Table 3). Looking only at the videos that appeared under the search terms 'hip arthritis', 'hip arthritis diagnosis' or 'hip arthritis symptoms', the diagnostic information quality was still poor in $78 \%$ (56 of 72). The information quality of educational-physician videos for the diagnosis of hip arthritis was significantly higher $(p<0.001)$ than educational-non physician videos and significantly higher $(p<0.001)$ than videos of the remaining categories combined, respectively. However, there were still only $26 \%(n=14)$ of all educational-physician videos of moderate quality and $4 \%(n=2)$ of excellent quality.

YouTube is a poor information source for the treatment of hip arthritis. In $86 \%(\mathrm{n}=114)$, videos provided poor information quality. Eleven percent $(n=15)$ of videos had a moderate quality and only $3 \%(n=4)$ an excellent quality (Fig. 2; Table 3). The quality of information for the treatment of hip arthritis was significantly higher $(p=0.005)$ than the quality of information for the diagnosis of hip arthritis. Educationalphysician videos had a significantly $(\mathrm{p}<0.001)$ higher quality than educational-non physician videos for the treatment of hip arthritis. However, educational-physician videos had significantly $(p<0.001)$ less views per day and significantly $(\mathrm{p}<0.001)$ less 'likes' compared to educational-non physician videos, despite a higher quality of information for the diagnosis and treatment of hip arthritis. The quality of information for the treatment of hip arthritis was significantly higher $(p=0.005)$ than the quality of information for the diagnosis of hip arthritis.

The second search identified 216 duplicates out of 302 videos $(72 \%)$. An additional 25 videos were excluded because they did not meet the defined inclusion criteria, leaving 61 videos for an assessment of diagnosis and treatment information quality. The mean diagnostic information quality of the 61 videos which were identified in the second search was 1.3 (SD 2), and the mean treatment information quality was 1.7 (SD 2.4). There was no difference in the diagnostic $(p=0.927)$ and the treatment $(p=0.222)$ information quality comparing the 133 videos of the initial search with the 61 videos of the second search.

\section{Discussion}

Patients increasingly access YouTube for further information in order to play a more active role in their personal health care decisions. As YouTube is a non peer-reviewed platform, physicians and patients should be aware of the variable quality of information and the different sources of health information. The quality of YouTube information has already been evaluated for different medical specialties such as internal medicine [23-25], urology [26], otorhinolaryngology [27] and neurology [28]. In the orthopaedic field, two recent studies have assessed the quality of information on YouTube concerning knee arthrocentesis [29] and femoroacetabular impingement [11], respectively. The quality concerning the diagnosis and treatment of hip arthritis has not been previously studied. We therefore asked the following research questions: (1) What is the information quality of YouTube videos related to the 
Fig. 2 Diagnostic and treatment information quality for all videos analyzed. YouTube is a poor information source for the diagnosis and treatment of hip arthritis

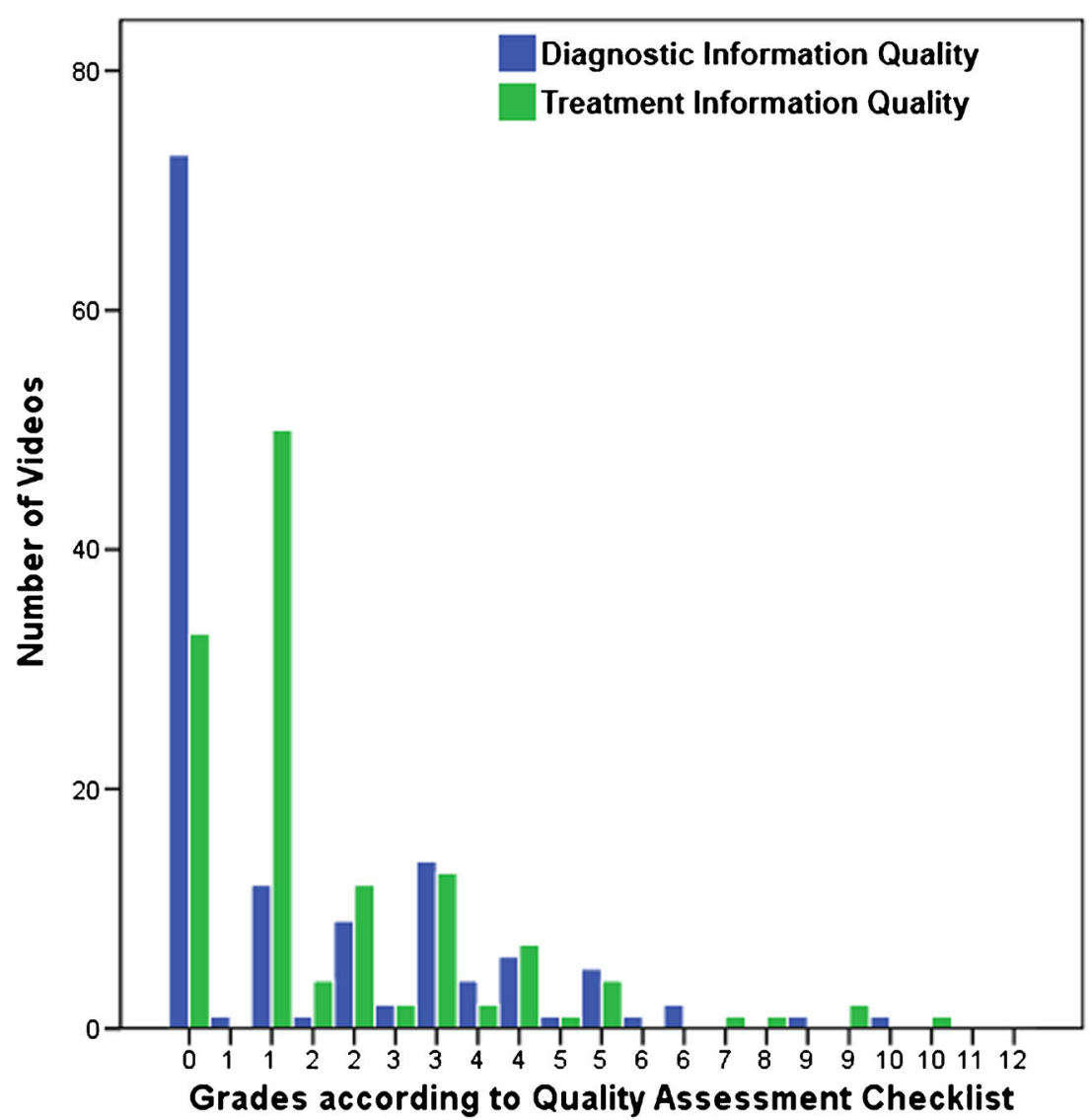

diagnosis of hip arthritis and (2) what information for the treatment of hip arthritis can be found on YouTube?

We acknowledge the following limitations: first, there is no validated tool to assess the quality of video-based medical information. Following the approach of MacLeod et al. [11] a new quality assessment checklist for the diagnosis and treatment of hip arthritis was developed. The grading scale had an excellent inter-observer and intra-observer reliability demonstrating the high internal consistency of the grading scale. Second, the utilized grading scale quantitatively assessed the amount of true and accurate content; however, it does not take into account whether a video provided false information. Third, the study did not assess whether patients felt that videos were good. Yet, the number of views per day and likes are indicators of whether patients considered videos useful.
Fourth, knowledge available on YouTube is constantly evolving. The second search on September 22, 2015 identified 23 new videos which were released after the first search. However, we could demonstrate that the information quality is not influenced by new content and remains unchanged at a very low level despite the new videos. Finally, videos related to inflammatory hip arthritis were excluded as inflammatory conditions require different diagnostic and therapeutic concepts.

The symptoms associated with hip arthritis can have an insidious onset. The typical patient is in his fifties or sixties and reports pain in the affected groin as the first symptom. Stiffness, limitations with walking and alternated gait patterns are also common and may be a presenting feature [30]. In most cases, the diagnosis of hip arthritis is not challenging
Table 3 Diagnostic and treatment information quality for each category

\begin{tabular}{lll}
\hline Parameter & Diagnostic information quality & Treatment information quality \\
\hline Educational-physician $(\mathrm{n}=54 ;$ mean $)$ & $2.3(\mathrm{SD} 2.2)$ & 2.7 (SD 2.5) \\
Educational-non physician $(\mathrm{n}=50 ;$ mean $)$ & $0.7(\mathrm{SD} 1.4)$ & $1.0(\mathrm{SD} 0.8)$ \\
Commercial $(\mathrm{n}=8)$ & 0 & 0 \\
Technique ( $=10 ;$ mean) & $0.3(\mathrm{SD} 0.9)$ & 1.1 (SD 0.5) \\
Personal testimony ( $=10 ;$ mean) & $1.7(\mathrm{SD} 1.4)$ & 1.8 (SD 1.2) \\
Other $(\mathrm{n}=1)$ & 0 & 0 \\
\hline
\end{tabular}

Educational-physician videos had a significantly $(\mathrm{p}<0.001)$ higher quality than videos of the other categories 
for medical professionals. For patients, however, the condition may be very confusing. Consequently, patients may access YouTube to gather further information about hip arthritis. The present study is relevant for physicians and patients alike. It demonstrates that YouTube videos are a poor source for accurate information concerning the condition and its proper diagnosis. These findings provide a basis for physicians to advise patients on the pitfalls of using YouTube as an information source for the diagnosis of hip arthritis. The majority of videos only provide a brief description of the disease. Overall, there were only three videos with excellent quality ( $>7$ points) according to the diagnostic information quality assessment checklist. One of these videos ('Hip Pain \& Arthritis: Evaluation \& Treatment'; https://www.youtube. com/watch? $=4$ naBSaEJA5Y) scored 12 out of 12 points. In 39 minutes, the clip carefully described the anatomy of the hip, the pathogenesis of arthritis and all aspects of a proper diagnosis. The other two videos had a similar quality of 9 points ('Total Hip Replacement Part 2: Symptoms \& Evaluation'; https://www.youtube.com/watch?v= PxUW27mOG_o) and 10 points ('Hip Pain and Arthritis Treatment Webinar'; https://www.youtube.com/watch?v= drL2VEOuwNk), respectively.

The present study demonstrates that online YouTube videos do not provide sufficient information about the possible treatment options of hip arthritis. There is good evidence for non-operative interventions as the first step on the treatment ladder. Patient education [31], physiotherapy [32-34], weight reduction [35], non-steroidal anti-inflammatory drugs [36] and injections into the arthritic hip [37] can successfully relieve pain, reduce stiffness and improve the quality of life for a certain period of time. Patients with the diagnosis of hip arthritis might access YouTube for more information about the different treatment options. This study showed that the available videos have a narrow focus and are therefore of poor quality. Consequently, available videos are not helpful for patients searching for more detailed information on the treatment of hip arthritis. Most videos classified as 'educational-non physician' were uploaded by physiotherapists. These videos are very popular on YouTube with more 'likes' and views per day than clips of any other category. However, 'educational-non physician' provided a poor quality of information regarding the treatment of hip arthritis (mean, 1 of 12 points). Most of these videos are concerned with one to two hip muscle strengthening exercises. Preoperative physiotherapy can be very beneficial for an improvement of pain, daily functioning and hip range of motion [34, 38]. However, it remains questionable whether the demonstration of a few exercises alone is sufficient to achieve a tangible benefit. Only after conservative treatment has failed, total joint replacement is the treatment of choice [4]. The present study showed that the information quality for the treatment of hip arthritis is higher $(p=0.005)$ compared to the information quality related to the diagnosis of the pathology. Yet, there were still only five videos identified using the search terms 'hip arthritis treatment' and 'hip replacement' with an excellent quality ( $>7$ points) according to the treatment information quality assessment checklist. Two videos were recordings of talks given by physicians. These videos provided a good overview but were not very appealing and not innovative. This was also reflected in only a few views per day on average. The third video scored 10 points in the treatment and diagnostic checklist and has already been mentioned above. The fourth video (https://www.youtube. $\mathrm{com} /$ watch? $=0-\mathrm{O} 8 \mathrm{IFzV} 8 \mathrm{Nc}$ ) was very popular with 333 views per day and 800 likes. It had two components: in the first half, an orthopaedic surgeon explained the treatment options; in the second half, the surgeon performed a hip replacement and gave comments during the procedure. The high number of views per day is an indicator that patients considered this video good and helpful. Lastly, the video 'Hip Pain \& Arthritis: Evaluation \& Treatment' (https:// www.youtube. com/watch? $\mathrm{v}=4$ naBSaEJA5Y) scored 12 points as it discussed all relevant aspects of proper treatment. The video was a recording of a talk given to a residential community. The presenting physician used video material and illustrated a complex issue in an understandable fashion. This video is an excellent example of what future videos could look like. However, it is critical to mention that none of these studies explicitly discussed the possible complications such as infection, periprosthetic fracture and dislocation that might be associated with total hip replacements. The results of this study are in line with MacLeod et al. [11] who showed that YouTube videos pertaining to femoroacetabular impingement have a low quality.

\section{Conclusions}

The present assessment of YouTube video material demonstrates that hip arthritis diagnosis and treatment information is overall insufficient. These findings provide a basis for physicians to advise patients on the pitfalls of using YouTube as an information source for hip arthritis diagnosis and treatment. The exchange of video-based information is going to rapidly grow within the next few years and videos are going to become the primary source of information. High quality educational videos are important to further guide patients on the way from the diagnosis of hip arthritis to its proper treatment. The medical community, therefore, should use the opportunity to define gold standards for comprehensive and innovative evidence-based educational videos addressing the diagnosis and treatment of hip arthritis. 
Acknowledgments Open access funding provided by Medical University of Vienna. We thank Mr. Paul Kolbitsch for technical assistance with this study.

\section{Compliance with ethical standards}

Conflict of Interest The authors declare that they have no conflict of interest.

Open Access This article is distributed under the terms of the Creative Commons Attribution 4.0 International License (http:// creativecommons.org/licenses/by/4.0/), which permits unrestricted use, distribution, and reproduction in any medium, provided you give appropriate credit to the original author(s) and the source, provide a link to the Creative Commons license, and indicate if changes were made.

\section{References}

1. Lawrence RC, Felson DT, Helmick CG, Arnold LM, Choi H, Deyo RA, Gabriel S, Hirsch R, Hochberg MC, Hunder GG, Jordan JM, Katz JN, Kremers HM, Wolfe F (2008) Estimates of the prevalence of arthritis and other rheumatic conditions in the United States. Part II. Arthritis Rheum 58(1):26-35. doi:10.1002/art.23176

2. Buckwalter JA, Saltzman C, Brown T (2004) The impact of osteoarthritis: implications for research. Clin Orthop Relat Res (427 Suppl):S6-15.

3. Jordan JM, Helmick CG, Renner JB, Luta G, Dragomir AD, Woodard J, Fang F, Schwartz TA, Nelson AE, Abbate LM, Callahan LF, Kalsbeek WD, Hochberg MC (2009) Prevalence of hip symptoms and radiographic and symptomatic hip osteoarthritis in African Americans and caucasians: the johnston county osteoarthritis project. J Rheumatol 36(4):809-815. doi:10.3899/jrheum. 080677

4. Ethgen O, Bruyere O, Richy F, Dardennes C, Reginster JY (2004) Health-related quality of life in total hip and total knee arthroplasty. A qualitative and systematic review of the literature. J Bone Joint Surg Am 86-A(5):963-974

5. Scott D (2006) Osteoarthritis of the hip. Clin Evid (Online) 2006.

6. Kurtz SM, Ong KL, Lau E, Bozic KJ (2014) Impact of the economic downturn on total joint replacement demand in the United States: updated projections to 2021. J Bone Joint Surg Am 96(8):624-630. doi:10.2106/JBJS.M.00285

7. Diaz JA, Griffith RA, Ng JJ, Reinert SE, Friedmann PD, Ton AW (2002) Patients' use of the internet for medical information. J Gen Intern Med 17(3): 180-185

8. Starman JS, Gettys FK, Capo JA, Fleischli JE, Norton HJ, Karunakar MA (2010) Quality and content of internet-based information for ten common orthopaedic sports medicine diagnoses. J Bone Joint Surg Am 92(7):1612-1618. doi:10.2106/JBJS.I.00821

9. Fox S, Rainie L (2002) E-patients and the online health care revolution. Physician Exec 28(6):14-17

10. rCisco Systems Inc. (2015) White Paper: Cisco Visual Networking Index. http://www.cisco.com/c/en/us/solutions/collateral/serviceprovider/ip-ngn-ip-next-generation-network/white_paper_c11481360.pdf. Accessed 29 Sept 2015

11. MacLeod MG, Hoppe DJ, Simunovic N, Bhandari M, Philippon MJ, Ayeni OR (2015) YouTube as an information source for femoroacetabular impingement: a systematic review of video content. Arthroscopy 31(1):136-142. doi:10.1016/j.arthro.2014.06.009

12. Blum A, Raymond A, Teixeira P (2015) Strategy and optimization of diagnostic imaging in painful hip in adults. Orthop Traumatol Surg Res 101(1 Suppl):S85-99. doi:10.1016/j.otsr.2014.11.002

13. Gandhi R, Perruccio AV, Mahomed NN (2014) Surgical management of hip osteoarthritis. CMAJ: Can Med Assoc J 186(5):347355. doi:10.1503/cmaj.121584
14. Chu CR, Millis MB, Olson SA (2014) Osteoarthritis: from palliation to prevention: AOA critical issues. J Bone Joint Surg Am 96(15):e130. doi:10.2106/JBJS.M.01209

15. Keurentjes JC, Pijls BG, Van Tol FR, Mentink JF, Mes SD, Schoones JW, Fiocco M, Sedrakyan A, Nelissen RG (2014) Which implant should we use for primary total hip replacement? a systematic review and meta-analysis. J Bone Joint Surg Am 96(Suppl 1):79-97. doi:10.2106/JBJS.N.00397

16. Davis AM, MacKay C (2013) Osteoarthritis year in review: outcome of rehabilitation. Osteoarthritis and cartilage / OARS, Osteoarthritis Research Society 21(10):1414-1424. doi:10.1016/j. joca.2013.08.013

17. Chong T, Don DW, Kao MC, Wong D, Mitra R (2013) The value of physical examination in the diagnosis of hip osteoarthritis. J Back Musculoskel Rehab 26(4):397-400. doi:10.3233/BMR-130398

18. Li B, Erdin E, Güneș MHI, Bebis G, Shipley T (2011) An analysis of anonymity usage. In: Domingo-Pascual J, Shavitt Y, Uhlig S (eds) Traffic monitoring and analysis. Traffic monitoring and analysis. Springer, Berlin, pp 113-116

19. Cronbach LJ (1951) Coefficient alpha and the internal structure of tests. Psychometrika 16:297-334

20. Streiner DL, Norman GR (1995) Health measurement scales: a practical guide to their development and use, 2nd edn. Oxford University Press, Oxford, p 231

21. Bland JM, Altman DG (2007) Agreement between methods of measurement with multiple observations per individual. J Biopharm Stat 17(4):571-582. doi:10.1080/10543400701329422

22. Altmann DG(1991) Practical statistics for medical research. Chapman and Hall, London

23. Pandey A, Patni N, Singh M, Sood A, Singh G (2010) YouTube as a source of information on the H1N1 influenza pandemic. Am J Prev Med 38(3):e1-3. doi:10.1016/j.amepre.2009.11.007

24. Pant S, Deshmukh A, Murugiah K, Kumar G, Sachdeva R, Mehta JL (2012) Assessing the credibility of the "YouTube approach" to health information on acute myocardial infarction. Clin Cardiol 35(5):281-285. doi:10.1002/clc.21981

25. Camm CF, Sunderland N, Camm AJ (2013) A quality assessment of cardiac auscultation material on YouTube. Clin Cardiol 36(2): 77-81. doi:10.1002/clc. 22080

26. Sood A, Sarangi S, Pandey A, Murugiah K (2011) YouTube as a source of information on kidney stone disease. Urology 77(3):558 562. doi:10.1016/j.urology.2010.07.536

27. Sorensen JA, Pusz MD, Brietzke SE (2014) YouTube as an information source for pediatric adenotonsillectomy and ear tube surgery. Int J Pediatr Otorhinolaryngol 78(1):65-70. doi:10.1016/j. ijporl.2013.10.045

28. Kerber KA, Burke JF, Skolarus LE, Callaghan BC, Fife TD, Baloh RW, Fendrick AM (2012) A prescription for the Epley maneuver: http://www.youtube.com/ Neurology 79(4):376-380. doi:10.1212/ WNL.0b013e3182604533

29. Fischer J, Geurts J, Valderrabano V, Hugle T (2013) Educational quality of YouTube videos on knee arthrocentesis. J Clin Rheumatol 19(7):373-376. doi:10.1097/RHU.0b013e3182a69fb2

30. Winter CC, Brandes M, Muller C, Schubert T, Ringling M, Hillmann A, Rosenbaum D, Schulte TL (2010) Walking ability during daily life in patients with osteoarthritis of the knee or the hip and lumbar spinal stenosis: a cross sectional study. BMC Musculoskelet Disord 11:233-1

31. Lorig KR, Mazonson PD, Holman HR (1993) Evidence suggesting that health education for self-management in patients with chronic arthritis has sustained health benefits while reducing health care costs. Arthritis Rheum 36(4):439-446

32. Arnold CM, Faulkner RA (2010) The effect of aquatic exercise and education on lowering fall risk in older adults with hip osteoarthritis. J Aging Phys Act 18(3):245-260 
33. Minor MA, Hewett JE, Webel RR, Anderson SK, Kay DR (1989) Efficacy of physical conditioning exercise in patients with rheumatoid arthritis and osteoarthritis. Arthritis Rheum 32(11):1396-1405

34. Czyzewska A, Glinkowski WM, Walesiak K, Krawczak K, Cabaj D, Gorecki A (2014) Effects of preoperative physiotherapy in hip osteoarthritis patients awaiting total hip replacement. Archives of Medical Science: AMS 10(5):985-991. doi:10.5114/aoms.2014.46218

35. Maly MR, Robbins SM (2014) Osteoarthritis year in review 2014: rehabilitation and outcomes. Osteoarthritis Cartilage 22(12):19581988. doi:10.1016/j.joca.2014.08.011

36. Baerwald C, Verdecchia P, Duquesroix B, Frayssinet H, Ferreira T (2010) Efficacy, safety, and effects on blood pressure of naproxcinod $750 \mathrm{mg}$ twice daily compared with placebo and naproxen $500 \mathrm{mg}$ twice daily in patients with osteoarthritis of the hip: a randomized, double-blind, parallel-group, multicenter study. Arthritis Rheum 62(12):3635-3644. doi: 10.1002/art.27694

37. Kruse DW (2008) Intraarticular cortisone injection for osteoarthritis of the hip. Is it effective? Is it safe? Curr Rev Musculoskelet Med 1(3-4):227-233. doi:10.1007/s12178-008-9029-0

38. Moulton LS, Evans PA, Starks I, Smith T (2015) Pre-operative education prior to elective hip arthroplasty surgery improves postoperative outcome. Int Orthop 39(8):1483-1486. doi:10.1007/ s00264-015-2754-2 